\title{
Oral Hygiene Practices and Prevalence of Dental Caries Among School Children in Niger State, Nigeria
}

\author{
Mohammed Aliyu ${ }^{1, *}$, Benedict Ubawike Akano² \\ ${ }^{1}$ Department of Physical and Health Education, Federal Collage of Education Kontagora, Kontagora, Nigeria \\ ${ }^{2}$ Department of Physics, Federal College of Education Kontagora, Kontagora, Nigeria \\ Email address: \\ muhammedaliyu503@gmail.com (M. Aliyu),drbuakano@yahoo.com (B. U. Akano) \\ ${ }^{*}$ Corresponding author
}

To cite this article:

Mohammed Aliyu, Benedict Ubawike Akano. Oral Hygiene Practices and Prevalence of Dental Caries Among School Children in Niger State, Nigeria. Central African Journal of Public Health. Vol. 5, No. 5, 2019, pp. 217-220. doi: 10.11648/j.cajph.20190505.16

Received: August 9, 2019; Accepted: September 6, 2019; Published: October 9, 2019

\begin{abstract}
The study investigated the oral hygiene practices and prevalence of dental carries among school children $(6-12$ years) in Niger State, Nigeria. A total of 477 pupils constituting 246 boys and 231 girls were used in the study. Stratified randomly sampling was used in selecting pupils from 9 public primary schools based on high, middle and low socio economic levels. Data obtained from this study was analysed using percentages and Chi-Square statistic at 0.05 level of significance. Results of the study revealed that, the practice of toothbrushing was not statisfactory among pupils for the reason that a large numbers of pupils $202(42.3 \%)$ did not brush their teeth at all. Also the prevalence and the number of dental caries were greater in the pupils of low socio-economic areas (66.5\%) than the others. The high and middle socio-economic areas had a similar overall prevalence of dental caries of $59.4 \%$ and $60.1 \%$ respectively. Toothbrushing behavior among the pupils was strongly related to the parental education and their socio economic statuses however, there was no statistical significance in the prevalence of dental caries among the socio-economic groups. Health education programmes such as, brushing of teeth twice daily, especially at night before going to bed to improve oral hygiene practices was therefore recommended.
\end{abstract}

Keywords: Oral, Dental, School Children, Hygiene, Prevalence

\section{Introduction}

Dental caries is a highly prevalent chronic sugardependent infectious disease, affecting calcified tissue of the tooth and causing demineralization of the inorganic portion with subsequent destruction of the organic substance [1]. Treating carious tooth does not mean the tooth will return to its original state. Adekele [2] opined that dental carries is a progressive, irreversible bacterial damage to the teeth in the mouth.

Dental caries is a typical oral medical issue in children and happens in people of all socio-Economic strata. Poor oral hygeine has likewise been believed to be very high in children particularly those living in rural areas.[3, 4] Lack of dental administrations at the Primary Health Care services level is said to represent the poor oral wellbeing status of rustic children in Nigeria.[2] Rural zones more often than not have less dental specialists per populace and are progressively denied, in this manner decreasing access to dental consideration for youngsters in these communities.[5, 6].

In Africa, including Nigeria, caries prevalence and mean DMFT (decayed, missing, and filled teeth) are low when contrasted with industrialized nations. The mean DMFT among 12-year-old school children in Africa is somewhere in the range of 0.5 and $2.6[7,8]$. Various epidemiological studies revealed decrease in the mean DMFT towards the worldwide objective of 3 at 12 years old in some industrialized nations of the world.

It is generally believed that three factors play a role in the development of dental caries; they are the host, the agent and the environments Fejerskov [9] believed that these factors interact to produce a variety of dental diseases at varying rates and intensities. The factors contributing to these variations could either be cultural, genetic, or environmental in nature. Dental caries has a worldwide distribution, regardless of sex, age and socio economic level.

Sheiham [10] and WHO [11] opined that dental caries is 
increasing over time especially since the relatively recent economic growth which has resulted in an increased consumption of refined sugar. It is higher in many developed countries than in other developing countries [12]. Lack of awareness of about oral hygiene practices has also contributed to the increase in dental caries. [11].

The purpose of this study was to investigate the oral hygiene practices and the prevalence of dental caries, and the various social and behavioral factors related to these problems among school children in Niger State. The following hypotheses were developed to guide the study:

i. There is no significant difference in the tooth brushing behaviors among the school children in three socioeconomic areas of Niger State.

ii. There is no significant difference in the dental caries among the school children in three socio-economic areas of Niger State.

iii. There is no significant difference in the educational status of the parents of the school children in three socio-economic areas of Niger State.

\section{Methodology}

This research was a cross-sectional survey using a multistage sampling technique of public primary schools in different areas of the state using their socio economic levels. The levels constitute:

A.High socio-economic areas (Bosso LGA in Minna town).

B. Middle socio-economic areas (Kuta LGA).

C. Low socio-economic areas (Paiko LGA).

Two (2) schools were selected in area A, four (4) schools in area B and three (3) schools in area C. using stratified random sampling.

Simple random sampling technique was then used in selecting 477 pupils constituting 160, 153 and 164 pupils sampled in areas A, B and C respectively. The sample was selected by cluster sampling in primary three classes, in other to ensure a stratified sample with regards to the pupils academic class, area and gender.

The diagnostic criteria of WHO regarding oral health surveys was used [11]. The detail of aim and typed of the study was explained to the head teachers and teachers of the schools, then classes and pupils were chosen as described before. The pupils were informed about the nature and purpose of the study. The researcher interviewed each child and the two-trained research assistants, using a specially prepared validated and pretested questionnaire. This was followed by an oral examination under good illumination. Other demographic data of the pupils were obtained from the pupils files available in schools.

The pupils were divided into two subjective groups namely; the tooth brushing group and the non-tooth brushing group according to their tooth brushing behavior. The tooth brushing group was further subdivided into three subjective subgroups as follow first those who regularly brushed their teeth in the night to keep the teeth clean from food debris during night hours, second group are those who brushed their teeth in the morning only for cosmetic reasons rather than decreasing the teeth and third group are those who brushed are other times.

Data obtained was analysed using percentages and Chi square statistic.

\section{Results}

In all, 477 pupils were examined for dental caries and oral hygiene practices. 246 boys and 231 girls, similar levels of pupils were taken from each area, since all the pupils used were in primary three (see table 1).

The differences in the educational status of parents in the three areas were statistically significant (at $\mathrm{P}<0.005$ ), which is clearly indicative of the difference in socio economic

Tab levels in the different areas of the study (see table 2).

Table 1. Composition of the sample according to the area, sex, tooth brushing behavior and dental caries.

\begin{tabular}{|c|c|c|c|c|c|c|c|c|c|}
\hline \multirow{2}{*}{ Area } & \multirow{2}{*}{ Boys } & \multirow{2}{*}{ Girls } & \multirow{2}{*}{ Total } & \multicolumn{4}{|c|}{ Toothbrushing Behaviour } & \multicolumn{2}{|c|}{ Dental Caries } \\
\hline & & & & No & Night & Morning & Other & No & Yes \\
\hline \multirow{2}{*}{ A (high socioeconomic Level) No \% } & 83 & 77 & 160 & 33 & 42 & 33 & 55 & 65 & 95 \\
\hline & & & 33.5 & 20.6 & 26.3 & 20.6 & 34.4 & 35 & 59.4 \\
\hline \multirow{2}{*}{ B (Middle Socioeconomic Level) No \% } & 78 & 75 & 153 & 60 & 19 & 31 & 44 & 61 & 92 \\
\hline & & & 32.1 & 39.0 & 14.1 & 20.3 & 28.3 & 39.9 & 60.1 \\
\hline C (Low socioeconomic Level) No \% & 85 & 79 & 164 & 109 & 7 & 23 & 24 & 55 & 109 \\
\hline \multirow{2}{*}{ Total No. \% } & 246 & 231 & 477 & 202 & 68 & 87 & 123 & 181 & 295 \\
\hline & & & 100 & 42.3 & 14.3 & 18.2 & 25.8 & 37.9 & 62.1 \\
\hline
\end{tabular}

Table 2. Chi-Square $\left(X^{2}\right)$ result on toothbrushing behaviors, dental caries and educational status of parents.

\begin{tabular}{lllll}
\hline Variable & Calc. $\mathbf{X}^{2}$ value & Df & Crt. Value & Decision on Ho \\
\hline Toothbruishingbehaviors & 118.6 & 6 & 18.5 & significant @ $<=0.005$ \\
Dental caries & 3.412 & 2 & 5.99 & Not significant @ P $>0.05$ \\
Parents educational status & 97.8 & 6 & 12.59 & Significant @ P $<=0.05$. \\
\hline
\end{tabular}




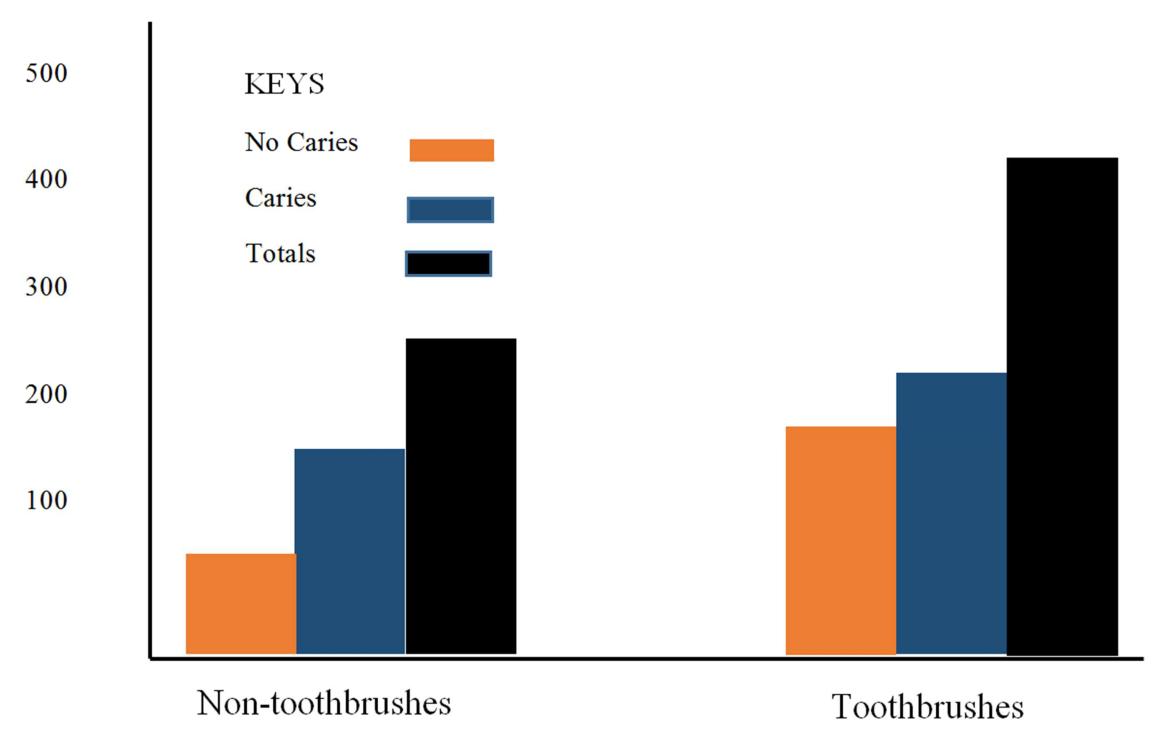

Figure 1. Number of caries for Non-toothbrush users and Toothbrush users.

Table 1 and Figure 1 revealed that $202(42.3 \%)$ of pupil did not brush their teeth. In area A, $33(20.6 \%)$ pupils did not brush their teeth, whereas in in B 60 (39\%) did not brush their teeth, and area $\mathrm{C}$ had highest number of nontoothbrushers with 109 (66.5\%) All types of tooth brushing behavior were in descending order according to the social status of each area.

Among all, regular night toothbrushers were 68 (14.3\%) of the 477 pupils, while $87(18.2 \%)$ brushed in the morning only; $123(25.8 \%)$ brushed at other times.

Of the 68 regular night toothbrushers, only $6(8.8 \%)$ had brushed for more than 4 years; the majority 39 (57.4\%) had been brushing for less than 2 years.

The prevalence of dental caries in this sample was $62.1 \%$; one or more tooth might be decayed in the same child.

The prevalence and the number of dental caries were greater in area $\mathrm{C}$, the low socio-economic areas (66.5\%) than the others. Areas A and B had a similar overall prevalence of dental caries (59.4\% and $60.1 \%$ respectively). The difference was not statistically significant at $\mathrm{p}>0.05$ (see table 2 ).

However, among the 202 pupils who did not bush their teeth, $67(33.2 \%)$ had no dental caries, compared with 116 of $278(41.7 \%)$ for all those who brushed. The difference in dental caries between non-toothbrushers and toothbrushers was statistically significant at $\mathrm{p}<0.005$ (see figure 1 and table 2).

\section{Discussion}

This study revealed that the practice of toothbrushing was not statisfactory among subjects for the reason that a large numbers of pupils $(42.3 \%)$ of the sample did not brush their teeth at all. Although area three had the largest number of the non-toothbrushers.

Toothbrushing behavior among the pupil was strongly related to the parental education and their socio economic statuses. This could be attributed to the awareness created by continuous parental instruction and/or to the imitation behavior of these children, as the children of parents in high socio economic level and those with parents who had higher education brushed their teeth regularly.

The prevalence of dental caries in this study was slightly higher among boys than girls, which differ from other studies [13]. Although, the difference was not statistically significant. Dental caries, was encountered less frequently among the toothbrushing group, a finding in line with Holt et al [14] and Legler, et al [13]. The higher prevalence of dental caries in area three is not in line with the finding of Olsson [15] which than those with of lower socio economic levels. The results however, simulate the situation in industrialized countries, where dental problems, including dental caries, are more common in the lower social classes, this may probably due to greater use of artificial feeding in infancy, the ability to afford sweets and refined sugars, ignorance, and poor oral hygiene practices $[14,16,17]$.

\section{Conclusion and Recommendations}

This study shows that dental caries among the school children is dependent on the tooth brushing behavior and general oral hygiene practices of the pupils. It is therefore recommended that parents regardless of their socio economic levels should emphasize regular tooth brushing habits for their children in the morning and especially at night before going to bed, so as to make the mouth be free of the food debris which could cause the tooth to decay. Teacher are also implored to engage in health education campaign to ensure that children adhere to the good oral hygiene practices so as to avert this irreversible dental health problem.

\section{References}

[1] Mc Donald, R. E.; Stookey G. K \& Avery D. R (2004). Dental caries in the child and adolescent. In McDonald R. E \& Avery D. R (Ed). Dentistry for the child and adolescent, (9th Ed). p 219-263. St Louis. CV Mosby Company. 
[2] Adeleke, W (1998). Care of baby teeth. Lagos: Adadis publisher.

[3] Adekoya-Sofowora CA, Nasir WO, Oginni AO, Taiwo M. Dental caries in 12-year-old suburban Nigerian school children. Afr Health Sci 2006; 6: 145-50. Back to cited text no. 1 .

[4] Okolo S, Chukwu G, Egbuonu I, Ezeogu F, Onwuanaku C, Adeleke $\mathrm{O}$, et al. Oral hygiene and nutritional status of children aged 1-7 years in a rural community. Ghana Med J 2006; 40: 22-5. Back to cited text no. 2.

[5] Sofola OO. Implications of low oral health awareness in Nigeria. Niger Med J 2010; 51: 131-3. Back to cited text no. 3.

[6] Maserejian N. N., Tavares, M. A., Hayes, C., Soncini, J. A., \& Trachtenberg, F. L. (2008). Rural and urban disparities in caries prevalence in children with unmet dental needs: The New England children's amalgam trial. J Public Health Dent 2008; 68: 7-13.

[7] Petersen, P. E., Bourgeois, D., Ogawa, H., Estupinan-Day, S. \& Ndiaye, C. (2005). "The global burden of oral diseases and risks to oral health," Bulletin of the World Health Organization, vol. 83, no. 9, pp. 661-669, 2005. View at Google Scholar View at Scopus.

[8] World Health Organization (2003). The World Oral Health Report, 2003, World Health Organization, Geneva, Switzerland, 2003.

[9] Fejerskov, O. (2003). Concepts of dental caries and their consequences for understanding the disease. Community Dentistry and Epidemonology, 29, 15-22.

[10] Sheiham, A. (2002). Dental caries in underdeveloped countries. In Guggenheim, B (Ed.) Cariology today. p 33-39. Basel: Karger Press.

[11] WHO (2004). Preventive methods and programmes for oral diseases. Geneva World Health Organization, (WHO Technical Report Series, No. 713). http://www.who.ch.

[12] Tamari J. W (1994). An assessment of oral disease among primary school children in Lebanon. I. Assessment of dental caries. International Dental Journal, 24, 407-415.

[13] Legler, D. W.; Al-Alousi, W \& Jamison, H. C. (1996). Dental caries prevalence in secondary school children in Iraq. Journal of Dental Research, 67, 1998-2004.

[14] Holt, R; Joels, D \& Winter, GB (1992). Caries in preschool children. The Camden study. British Dental Journal, 153, 107109.

[15] Olsson, B. (1999). Dental health situation in privileged children in Addis Ababa, Ethiopia. Community Dentistry and Oraal Epidemiology, 9, 71-76.

[16] WHO (1997). Oral health surveys. Basic methods, (5th Ed), Alexandria, World Health Organization Regional Office for the Eastern Mediterranean, 8-9.

[17] Truin, G. J; Konig, K. C. \& Kalsbeek, H. (1993). Trends in dental caries in the Netherlands. Advances in dental Research, $7,1,15-8$. 